\title{
PASADO, PRESENTE Y FUTURO DE LOS BOSQUES DE LA PENINSULA IBÉRICA
}

\author{
Emilio FERNÁNDEZ-GALIANO
}

Todo induce a sospechar que la población de la Península Ibérica en el Paleolítico debió reducirse a unos millares de habitantes, distribuídos en comunidades poco numerosas, que vivían de la caza y de la recolección de frutos, lo que exigía un elevado grado de desarrollo del sentido ecológico para sobrevivir en las durísimas condiciones en que debió mantenerse su existencia. Este sentido ecológico se evidenciaba por el alto nivel de conocimiento que poseían sobre las plantas y animales, representado en las pinturas rupestres que se han conservado hasta nuestros días.

En esta época, nuestros antepasados vivían dentro del medio físico, en estrecha conexión con la naturaleza, siendo los bosques elementos protectores imprescindibles para el desarrollo de las actividades vitales, por lo que sus habitantes eran al tiempo que dependientes de ellos, protectores de los mismos por su elemental tipo de subsistencia.

En el tránsito hacia el Neolítico se produce un cambio que había de influir notablemente en la conservación de los bosques: el hombre aprende la domesticación de plantas y animales y se hace agricultor, ganadero y artesano, mejora sus condiciones de vida y aumenta notablemente su demografía. Todo ello repercutiría en la situación de los bosques, que habían de soportar el peso de estas transformaciones.

No obstante, nada autoriza a pensar que en las etapas prehistóricas los bosques españoles sufriesen graves agresiones ocasionadas por las actividades humanas, si bien la acción del hombre, condicionado por una climatología particular que comentaremos mas adelante, pudo degradar algunas formaciones forestales hasta las variantes de matorral mediterráneo, como consecuencia del carácter casi irreversible de algunas transformaciones.

Al hacerse el hombre agricultor se acentúa el carácter sedentario de su colectividad y construye viviendas en las que el material predominante es la madera utilizándola tambien para herramientas y utensilios diversos. Por otra parte, tanto la ganadería como la agricultura exigían mayores superficies, roturándose los bosques para establecer cultivos en muchos casos itinerantes, que se abandonaban al cabo de unos años, cuando los suelos quedaban exhaustos, o para formar pastizales estableciendo montes adehesados en los que se compatibilizaba el aprovechamiento de las hierbas con el de los frutos.

El desarrollo de la minería y la metalurgia contribuyó tambien en un elevado grado al mayor consumo de leña y carbón y el establecimiento de las colonias de otros pueblos mediterráneos, con el consiguiente aumento del comercio de metales, 
estimuló tambien la presión sobre los bosques.

De todas formas, esta presión se manifestó de manera más aguda en la periferia de la Península, en las comarcas litorales, donde se establecieron las primeras colonias y se produjo un notable desarrollo demográfico. En las comarcas del interior, más deshabitadas, el bosque se conservó más o menos intacto; a este hecho se refieren algunos relatos de la época romana en los que se presenta nuestro país como un lugar excepcionalmente poblado de bosques. De esa época procede el personaje legendario del medio natural ibérico, la famosa ardilla que era capaz de recorrer el país de norte a sur saltando de rama en rama, que nos hizo cavilar no poco en nuestros años juveniles sobre cómo se las arreglaría para cruzar los ríos y algunas comarcas de carácter estepario. No obstante, se calcula que al comienzo de la Edad Media probablemente la mitad de la Península Ibérica había perdido ya su cobertura boscosa y aparecían amplias comarcas desprovistas de vegetación arbórea.

Es en la Edad Media y principios de la Edad Moderna cuando se acentúan las causas de la deforestación o deficiente mantenimiento de los bosques. Tres hechos fundamentales de nuestra historia cultural contribuyen a ello: la reconquista española del territorio ocupado por los árabes, el incremento y fomento del pastoreo y la demanda creciente de madera para usos industriales, en especial para la construcción de barcos.

La peculiar forma de hacer la guerra durante los ocho siglos de reconquista, con la destrucción masiva de la cobertura vegetal de grandes superficies y la cesión de los territorios conquistados a nuevos pobladores, provocó una merma considerable de las áreas forestales, a pesar de las numerosas ordenanzas reales que dictaban normas sobre su conservación y explotación racional.

El pastoreo de ovinos y caprinos, principalmente en régimen de trashumancia, era una práctica muy común que procedía de tiempos muy remotos. Su importancia económica llegó a ser muy grande, lo que condicionó la dedicación de grandes extensiones del territorio a esta actividad, bien en propiedades de gran tamaño o en mancomunidades de pueblos reunidos. Tanta importancia alcanzó, que a mediados del siglo XIII el rey Alfonso el Sabio creó "El Honrado Concejo de la Mesta de Pastores", en cuyas tareas figuraba la ordenación y protección de la trashumancia y el establecimiento de los caminos por los cuales habían de circular los rebaños, principalmente las cañadas reales y sus ramificaciones (veredas y cordeles).

El Concejo de la Mesta fue acumulando poder, que llegó a ser muy grande en tiempos de los Reyes Católicos, dando lugar a una serie de disposiciones que en su aplicación causaron graves perjuicios a la agricultura y a los bosques. Los ingresos que producía el ganado eran muy elevados (en un tiempo en que la lana constituía un producto de gran importancia económica, y la lana producida en España era de primera calidad) y constituían un apoyo financiero muy importante para el Estado, que trataba con ellos de resacirse del agotamiento económico originado por las contínuas luchas contra moros y judíos para reconquistar los territorios perdidos en épocas anteriores.

La prioridad que se otorgó a la explotación ganadera motivó la desaparición de gran parte del sotobosque, con lo que se dificultaba la regeneración natural; los pastores utilizaban mucho ramaje para alimento de los ganados, favoreciendo el ramoneo y se calentaban y construían cabañas con los productos del bosque; además, se 
practicó la quema de grandes extensiones de bosques para ampliar las superficies de pastos. Muchos terrenos quedaron así privados de vegetación arbórea y sometidos a un pastoreo excesivo, quedando fácilmente expuestos a la erosión.

El tercer hecho que influye sobre la explotación de los bosques en los comienzos de la Edad Moderna es la progresiva utilización de la madera en los usos industriales y el enorme consumo de los astilleros. En tiempos de los Reyes Católicos se construían barcos de 500 a 1000 toneladas. Si se tiene en cuenta que cada 100 toneladas consumían unos 1000 metros cúbicos de madera de la mejor calidad, que en 1573 la flota española llegó a contar con 300.000 toneladas de registro bruto y que la vida activa de los barcos no era muy larga, puede calcularse la enorme sangría que suponía su construcción y mantenimiento para los bosques españoles y esta situación persiste a lo largo de varios siglos durante los cuales España mantuvo su hegemonía en los mares, prácticamente hasta que se construyeron los barcos de hierro. La Gran Armada de Felipe II, cuyo centenario de su derrota se cumple este año, representaba más de un millón de metros cúbicos de madera.

En la mitad del siglo XVIII la deforestación había alcanzado cotas preocupantes, lo que dió lugar a que en la época de la dinastía borbónica se dictasen ordenanzas encaminadas a la conservación de bosques e incluso al incremento de los mismos, pero siempre con vistas a su futura explotación y no porque se considerasen bienes que contribuían al equilibrio biológico, concepto todavía no asumido por unas generaciones que consideraban la Naturaleza como un elemento a explotar para el bienestar humano, sin gran preocupación por el futuro. Además, las legislaciones protectoras, hasta mediados del siglo XIX, se promulgaban en períodos de gran inestabilidad política y no regían durante largo tiempo o, lo que era peor, eran derogadas para imponer otras de tipo contradictorio, situación un tanto anárquica que fue muy perjudicial para la cobertura vegetal de nuestra nación.

Solamente a finales del siglo XVIII se imponen poco a poco las ideas de los reformadores, influídos por el movimiento cultural europeo de la Ilustración, que se interesó por los problemas agrícolas y de las que emergieron las primeras inquietudes conservacionistas, si bien todas las medidas que se sugerían no eran del todo acertadas debido a que se basaban en planteamientos que, muchas veces, pecaban de simplistas.

Y así nos encontramos, a principios del siglo XIX, con un país en el que una gran parte del territorio ha sufrido una intensa deforestación, panorama que hace que se levanten comentarios de no pocos hombres ilustres de la época. Así, Bowles en su "Introducción a la Historia Natural", dice, refiriéndose a la Península Ibérica: "No se puede considerar sin lástima la escasez de árboles y lo árido que se presenta su terreno en la mayor parte de sus provincias interiores. Reparando solamente lo que pasa en Madrid, se hallará lo mucho que se ha destruído de lo que se plantó en tiempo de Felipe II y lo poco que se ha repuesto. Su dehesa, que fue en otro tiempo "buen monte de puerco y oso" es ahora la imagen de la aridez, pudiendo ser un bello monte de encina, para lo cual es muy a propósito su terreno de arcilla mezclada con arena".

La poco satisfactoria situación de la cobertura boscosa al empezar la revolución industrial que da comienzo a nuestra era, podría atribuirse exclusivamente a la desidia y olvido de los gobernantes de épocas anteriores, pero eso nos conduciría a conclusiones erróneas, pues desde la Edad Media abundaron los intentos de proteger a los bosques de la codicia humana por medio de legislaciones a diferentes niveles 
(leyes, fueros, ordenanzas, etc.), pero en la mayor parte de los casos, debido a circunstancias diversas, no se alcanzó el propósito que se perseguía.

La Edad Media recogió las enseñanzas agrícolas de los romanos, bien por medio de los sabios cristianos o de los musulmanes españoles, muy conocedores de la agricultura y del cultivo de los árboles, cuyos postulados se aplicaron en gran parte a la jardinería árabe. Pero la obra que quizá influyó más en los denodados esfuerzos que se hicieron por mantener y cuidar nuestro patrimonio natural vegetal fue la "Agricultura General" de Gabriel Alonso de Herrera, cuya primera edición corresponde a 1513. El éxito de dicho libro se demuestra por haberse publicado de él 28 ediciones, de las cuales una de las más valiosas es la aparecida en 1818 patrocinada por la Real Sociedad Económica Matritense, con anotaciones de científicos de la Ilustración, como Arias (Sandalio), Boutelou (Claudio), Clemente, Lagasca, etc. La lectura detenida de este libro nos ilustra sobre los elevados conocimientos de aquellos hombres de principios del siglo pasado y de sus inquietudes acerca de la situación de los bosques, así como sus predicciones para el futuro. Sirvan de ejemplo los párrafos con que anota D. Sandalio Arias el capítulo XXIV, De los encinares, llenos de dramatismo y de premonición: "Como Herrera omitió en este capítulo el dar a conocer y aún el enumerar algunas de las muchas y esquisitas especies de encina que tenemos en las diversas provincias de España, cuales son los robles y alcornoques, al mismo tiempo que guardó el más profundo silencio acerca del escandaloso abuso, que ya en su tiempo se notaba, como en el nuestro, en la tala y aniquilación de los montes y arbolados, sin haber quien trate de fomentarlos sino de destruirlos, nos vemos en la necesidad de decir algo sobre ambos puntos, repitiendo con harta más razón que nuestros mayores: tiempo llegará en que los que nos sucedan se quejen de nosotros, y aún maldigan nuestra morosidad e indolencia, porque habiendo gozado de lo que nos dejaron otros, no supimos adoptar los medios convenientes para reemplazar la pérdida causada por el consumo".

"Se ha tocado ya cuanto predijo sobre este punto el celoso Monarca Felipe II, y no hay pueblo alguno que no experimente, más o menos, los funestísimos efectos de la escasez de maderas de construcción, de combustible, y de una gran parte del alimento que por espacio de tantos siglos suministraron a los hombres, para sus ganados, los extensos encinares. ¿Cuál será la suerte de nuestros venideros a la vista del estado de desolación en que de día en día van quedando los montes y arbolados en España?. ¿Cuántos y cuán justos serán sus lamentos y sus imprecaciones contra nuestra indolencia al observar que la mayor parte de los dilatadísimos terrenos baldíos, y en los eriales infructíferos que registra su vista, estuvieron un día pobladísimos de encinas, robles, alcornoques y otros muchísimos árboles? ¿Qué dirán cuando sepan que las cuestas de las montañas y cerros que hoy presentan la más horrenda imagen de la esterilidad y aridez, formaban muy poco antes la más agradable y útil perspectiva? ¿Cómo podrán dejar de enfurecerse contra los que no sólo les han privado de los inmensos recursos que prestan los arbolados de esta especie, sino que, con haberlos talado tan desmedidamente sin que jamás hayan pensado en reponerlos, les han privado también de los abundantísimos y multiplicados manantiales de aguas que fertilizaron un tiempo las colinas, los valles y llanuras, ya áridas y secas por falta de aquellos? Ello es cierto que a la par que han desaparecido los bosques que poblaban las cumbres de las altas montañas, sus lomas y los cerros que se levantan en muchos puntos, han 
desaparecido también los copiosos manantiales que en ellas había, y se ha cambiado sensiblemente la temperatura de nuestra atmósfera".

La cita es demasiado larga, pero muy ilustrativa. La edición de Alonso de Herrera anotada por la Sociedad Económica Matritense se vió muy mermada por un incendio y quizá por ello no alcanzó la difusión que merecía. Es un obra fundamental para comprender el alcance de los conocimientos en materia ambiental de los hombres de la Ilustración. También, los párrafos transcritos nos ayudarán a comprender cual era la situación de la cobertura vegetal de España al comienzo de la revolución industrial, que tuvo lugar hace poco más de un siglo.

La revolución industrial, que en los países centroeuropeos catalizó sensibles cambios que afectaron a la cobertura vegetal, si bien con consecuencias muy distintas de los mediterráneos, llegó a España con cierto retraso, lo que no impidió que se produjesen nuevos hechos que repercutieron de manera diversa hasta nuestros diás.

El consumo de madera para usos industriales sufrió notables transformaciones, si bien se produjeron sustituciones que no alteraron las cifras de utilización, sino que, más bien, en ocasiones se aumentaron. Se redujo el uso de la madera en la construcción de barcos (todavía, en 1868, una fragata de unas 700 toneladas, construída en Cartagena, consumió 7000 metros cúbicos de madera), pero se aplica a otras necesidades, como la construcción de ferrocarriles, tanto en infraestructura como en material de transporte.

Hasta después de nuestra guerra civil fue normal en las zonas rurales el uso de la madera como combustible, debido a su baratura y a su fácil accesibilidad, y solamente al principio de la década de los años 1950 se comenzó a abandonar la práctica del aprovechamiento de los montes comunales para leña. A ello contribuyó la comercialización de los derivados del petróleo (especialmente los gasificados), la elevación del nivel de vida y el éxodo de la población rural, que emigraba a las ciudades.

Por otra parte, contemporánea con la revolución industrial, se comienza a desarrollar en los niveles políticos y.culturales del país una preocupación por la conservación del medio natural que cristalizará en la adopción de una serie de medidas acertadas, pero también se procedió durante todo el siglo XIX a la promulgación de una legislación vacilante y no pocas veces contradictoria, producto de la agitada vida política española de entonces, cuya apliçación fue causa de no poco deterioro ambiental, cuyos efectos sufrimos todavía.

La característica más generalizada, desde el punto de vista climático, de los bosques españoles, especialmente los de carácter más mediterráneo, es la presencia, más o menos duradera, de una época de sequía estival acompañada de una elevación de las temperaturas, con unos inviernos bastante moderados, lo que condiciona un período vegetativo largo, con una interrupción (o una atenuación) veraniega, o bien, en comarcas con una severa continentalidad (como son muchas partes de elevada altitud del interior de la península), con interrupciones o limitaciones estivales e invernales.

En cuanto a las precipitaciones, no existe uniformidad sino, al contrario, una gran variabilidad; desde valores muy altos que permiten la instalación de formaciones forestales densas y potentes, hasta valores muy extremos que impiden o dificultan el mantenimiento de una cobertura arbórea. Es evidente que las agresiones al bosque en 
los lugares sometidos a esta diversificación de valores pluviales supondrán, forzosamente, unos efectos muy diversos, y esto es muy de tener en cuenta a la hora de valorar los hechos pasados que han conducido a la situación actual, especialmente si se considera que la mayor parte de España está sometida a las influencias climáticas mediterráneas, con la única excepción de porciones de su territorio de clara influencia oceánica.

En la evolución de las regiones mediterráneas, desde los tiempos más remotos hasta nuestros días, se observa una contínua utilización del bosque para el mantenimiento total o parcial de las poblaciones que responde a una serie de características, entre ellas la multiplicidad de usos. Efectivamente, el bosque mediterráneo ha venido proporcionando productos de uso muy variado, como son: corcho, leña, carbón, maderas diversas, frutos, ramón, hierba, resina, miel, caza, etc. Se utilizó también como cultivo itinerante, aprovechando las reservas húmicas de sus suelos, y desempeñó el papel de reservorio de agua para cultivos intensivos en zonas deforestadas. Algunos de estos aprovechamientos condujeron a veces (debido, en parte, a causas sociológicas, políticas o circunstanciales), a la supresión de los bosques de extensas comarcas, aunque se ha especulado mucho con la deforestación española, que ha sido inferior a lo que aparentemente se supone. De los 50,5 millones de hectáreas que comprende el territorio español, 25,6 millones están actualmente cubiertos de vegetación forestal (bosques, matorrales, pastizales y espartales), de las que 11,8 millones corresponden a bosques, es decir; el 23,3\% de la superficie nacional, porcentaje superior a la media de la Comunidad Económica Europea.

Si bien la presión pastoral produjo en muchos casos deterioros en los bosques, por mantenerse excesiva o por dar lugar a abusos, es evidente también que catalizó utilizáciones de gran interés y compatibles con el mantenimiento de determinados tipos de vegetación, como las montaneras, el establecimiento de dehesas o el consumo de vegetales leñosos, con la consiguiente selección de especies y razas animales.

Pero quizá la forma más interesante de utilización tradicional de la vegetación desde las épocas más antiguas corresponda a la selección de especies arbóreas del bosque mediterráneo para su conversión en especies frutales agrícolas más o menos domesticadas. A este respecto, puede citarse el olivo, de origen claramente forestal, injertado en acebuche y después domesticado, circunstancia que concurre también en especies del Mediterráneo oriental, como algarrobo, almendro, higuera y varias más. La encina, el quejigo y el alcornoque sufrieron solamente una domesticación incompleta, aunque fueron objeto de notables mejoras en cuanto a la calidad de los frutos (selección muy lenta y, por tanto, muy antigua en determinados territorios adehesados) y en cuanto a su expansión, favorecida, indudablemente, por el hombre.

Aunque toda la historia de la humanidad se viene caracterizando por un relevo de generaciones, herederas todas ellas de los logros y descubrimientos de las anteriores, lo que ha permitido un progreso contínuo debido al carácter uniforme acelerado del proceso en virtud del cual cada generación supera a las anteriores, la actual generación ha conocido un desarrollo inédito hasta ahora y que, probablemente, será excedido en la próxima. Así, en la vida de una sola persona, en lo que se refiere a la 
conservación de la Naturaleza, hemos pasado de una preocupación protagonizada por unos indivíduos cultos, pero poco numerosos y poco representativos, a un clamor general a cargo de grandes colectividades que algunas veces responden más a estímulos emotivos que racionales.

La situación presente es heredera de numerosos errores del pasado que condujeron a la elaboración de planes políticos tendentes a corregirlos que más de una vez dieron como resultado la acumulación de un error sobre otro error. Así, desde los primeros años de nuestro siglo se emprenden acciones tendentes a corregir los pasados errores. Por un lado, procurando la regeneración de las masas forestales, alcanzando en bastantes casos éxitos notables. Por otro, repoblando, es decir, procurando dotar de cobertura arbórea a superficies en acentuado estado de degradación, no cubriéndose siempre el objetivo propuesto. La necesidad de utilizar especies arbóreas muy frugales en los terrenos muy degradados obligó a echar mano de especies resinosas de gran combustibilidad lo que, en el mejor de los casos, no condujo a la regereración de la vegetación, sino al establecimiento de disclimax muy alejadas de la cobertura natural originaria. Así, entre 1940 y 1982 se repoblaron en España casi tres millones de hectáreas con pinos, modificando en la mayoría de los casos la composición de las formaciones vegetales originales.

Nada conduce, pues, al optimismo con respecto a la situación actual del bosque español. La marginalización y el olvido de las comarcas forestales, debidos en gran parte a su baja productividad, se han traducido en un despoblamiento generalizado que ha empobrecido todavía más a las zonas montañosas (donde el porcentaje de bosques es mayor) y que ha motivado la disminución e incluso la decadencia de los tratamientos, aprovechamientos de leña y de frutos, embastecimiento de los pastos y abandono de los matorrales, procesos todos que conducen a una disminución de la diversidad vegetal.

Por otra parte, el aumento del número de incendios (en una gran proporción provocados por motivos sociales o económicos) y la presión de grupos financieros para establecer plantaciones de árboles productores de celulosa con maquinaria pesada, han contribuído a deteriorar el panorama y retrotraer algunas superficies al insatisfactorio estado inicial.

Sin embargo, la presión sobre los bosques no ha disminuído sino, al contrario, parece crecer. El empleo de nuevos materiales de construcción en unos aspectos ha reducido el uso de la madera pero en otros lo ha aumentado exigiendo tipos más selectos, como maderas para muebles. La subida de los precios para combustibles está obligando nuevamente al uso de la madera para calefacciones, especialmente en las áreas rurales. Y también el consumo de celulosa en multitud de sus aplicaciones aumenta continamente, lo que repercute en la demanda de maderas para ese destino.

Las ideas conservacionistas del pasado siglo (y aún del presente), que dieron lugar a la creación de los parques nacionales y reservas donde se practica una conservación a ultranza, han evolucionado hasta el extremo de considerar al hombre como un elemento más del ecosistema, del cual ha de vivir mediante una utilización racional de sus recursos. Ello nos lleva a considerar al bosque como un elemento vital, no sólo en sus aspectos económicos, sino en los estéticos o culturales.

Por otra parte, los cambios estructurales que se están produciendo en Europa con el desarrollo de la Comunidad Económica Europea, a la cual España pertenece, 
obligan a contemplar el futuro del bosque y matorral mediterráneos con una óptica a largo plazo y siempre teniendo muy en cuenta dicha pertenencia.

Esta situación obliga a prestar una gran atención a los bosques, muy especialmente a los correspondientes a áreas críticas, en lo que se refiere al mantenimiento de la diversidad biológica y la estabilidad de las formaciones forestales. El sostenimiento de estas áreas necesita de una importante actividad humana, ya que el tipo de ecosistemas mediterráneos estables convenientes para evitar desequilibrios, como la disminución de la diversidad, alteraciones de carácter hidrológico y los fuegos, debe inspirarse en nuevos planteamientos silvopastorales y en la promoción de vegetaciones protectoras que disminuyan los riesgos de incendios.

Los aproximadamente cincuenta años de repoblaciones con empleo casi exclusivo de especies resinosas nos han proporcionado grandes extensiones en las que se ha obtenido una cobertura vegetal que no tiene nada, o muy poco, que ver con la vegetación primitiva, pero de la que quedan retazos aprovechables. Debería impulsarse la "reconversión" de esta zonas, provistas ya en muchos casos de suelos medianamente viables, para promocionar el crecimiento de especies frondosas con la eliminación lenta y progresiva de las resinosas. Se trata, evidentemente, de una labor lenta a largo plazo, de las que no suelen complacer a los políticos, pero precisamente su lentitud justifica la urgencia en comenzarla.

Esta actitud debe complementarse con la creación de una red de espacios naturales protegidos que cubra los aspectos de representatividad y la protección de especies amenazadas por unas causas u otras. Este aspecto, por fortuna, se va teniendo en cuenta cada vez más y son notables los esfuerzos hechos en algunas Comunidades Autónomas en esta materia de protección del medio natural, entre ellas la andaluza.

Algunos productos de los bosques españoles, especialmente de las áreas de carácter más mediterráneo, se encuentran injustamente postergados, como maderas de buenas calidades de nogal, castaño, roble (sobre todo Quercus faginea y Q. canariensis, actualmente infrautilizados) u otros aprovechamientos, como el corcho, la montanera o el carbón. La potenciación de estas producciones, así como la utilización del ganado como instrumento económico en la gestión de los bosques aumentaría su interés, lo que contribuiría a su conservación.

Debería aprovecharse y fomentarse el proceso sociológico en virtud del cual se está desarrollando progresivamente un interés por la naturaleza, canalizándolo en forma de turismo, tanto nacional como extranjero, especialmente hacia las áreas boscosas del interior e incluso procurando de esta manera aumentar la población residente. La vegetación y el paisaje adquirirían así un cometido importante en lo referente a la promoción de la salud y del recreo y podría servir de marco complementario de nuevos asentamientos de carácter semi rural.

El futuro de nuestros bosques se presenta pleno de incertidumbres y dificultades si se contempla dentro del marco de la Comunidad Económica Europea. No parece que las perspectivas de fomentar la producción de pasta de papel y maderas (de no muy alta calidad) sean muy favorables. Los programas centroeuropeos de producciones forestales contemplan la producción de fuertes contingentes en llanuras de clima oceánico, mediante genotipos mejorados como sustitución de la agricultura intensiva productora de excedentes agrarios, y la competencia con ellos será muy difícil.

Así, pues, la gestión de los bosques españoles plantea nuevos retos de imagi- 
nación, y hay que ser en extremo prudentes en no acometer acciones que puedan resultar irreversibles, como actuaciones con maquinaria pesada, laboreo de pendientes, aterrazamientos, etc. que con tanta frecuencia se vienen practicando en España.

Por último, deben fomentarse y recibir importancia prioritaria las necesidades de investigación, experimentación y vigilancia contínua de los procesos, especialmente en lo que se refiere a estudios hidrológicos, experimentación de nuevas fórmulas pastorales, reconstitución y reconversión de la vegetación, recionalización de productos combustibles e importancia del entorno natural en la salud física y mental.

Málaga, 22 de septiembre de 1988

\section{B I B L I O G R A F I A}

ALONSO DE HERRERA, G. -1818-Agricultura general adicionada por la Real Sociedad Económica Matritense. Imprenta Real. Madrid.

BALGAÑON, M. -1985- Los bosques: evolución histórica, situación actual. El Campo, 98:25-30.

BOWLES, G. -1782- Introducción a la Historia Natural y a la Geografía Física de España (2 ed.). Imprenta Real. Madrid.

FERNANDEZ GALIANO, E. - 1983- El estado de la ciencia botánica española. Real Academia de Farmacia. Madrid.

FERNANDEZ GALIANO, E. - 1987- La biosfera y el hombre. Real Academia de Farmacia. Madrid.

FERRERAS, C. \& AZORENA, M.E. -1987- Los bosques. Alianza Editorial. Madrid.

GONZALEZ FERNALDEZ, F. -1988- Bosque y paisaje mediterráneos: pasado, presente y futuro. I. Jornadas Municipales sobre gestión y conservación de masas forestales. Conferencia.

PONZ, A. -1793- Viaje de España. Edición de Aguilar, Madrid, 1947.

RUBIO, J. -1988- Biogeografía. Paisajes vegetales y vida animal. Madrid.

Dirección del autor: Departamento de Biología Vegetal, II. Universidad Complutense. Madrid. 
